\title{
Role of Four-Dimensional Data Assimilation on Track and Intensity of Severe Cyclonic Storms
}

\author{
Radhika D. Kanase and P. S. Salvekar \\ Indian Institute of Tropical Meteorology, Pune 411 008, India \\ Correspondence should be addressed to Radhika D. Kanase; radhikakanase@gmail.com
}

Received 20 December 2012; Accepted 27 January 2013

Academic Editors: T. Georgiadis, A. Saha, and D.-Y. Wang

Copyright ( 2013 R. D. Kanase and P. S. Salvekar. This is an open access article distributed under the Creative Commons Attribution License, which permits unrestricted use, distribution, and reproduction in any medium, provided the original work is properly cited.

\begin{abstract}
To examine the role of four dimensional data assimilation (FDDA) on prediction of two Severe Cyclonic Storm (Aila (May 2326,2009 ) and Jal (Nov 4-8, 2010)), four numerical experiments are performed using WRF-ARW model with three nested domains having two-way interaction and physical parameterization schemes as CPS-BMJ, MP-WSM6, and PBL-YSU. In each experiment, the model integration is started prior to the formation of depression and continued till the observed landfall. For the experiment without FDDA, NCEP-FNL data alone is used as initial and boundary conditions and for the experiments with FDDA, additional observations are used. In all the experiments, FDDA is considered only in the outer domain upto 24 hrs of integration and then the inner domain is introduced. The results are examined in terms of surface circulation, vorticity, CSLP, MSW, and surface track error. FDDA-produced surface circulation and vorticity showed well-organized structure. For the case of Aila, the surface track (maximum track error: $281 \mathrm{~km}$ ) and landfall position $\left(88^{\circ} \mathrm{E} / 21.73^{\circ} \mathrm{N}\right)$ in FDDA experiment are predicted better than experiment without FDDA (track error: $445 \mathrm{~km}$ and landfall position $87.13^{\circ} \mathrm{E} / 20.37^{\circ} \mathrm{N}$ ) whereas the landfall time experiment without FDDA is closer to observations (between 09 and 12 UTC of May 25) than that of experiment with FDDA(06 UTC of May 25). When CSLP and MSW are examined, the overall intensity is well predicted with FDDA experiment except near to the landfall time. For Jal cyclone, FDDA played significant role to improve the landfall position $\left(80.16^{\circ} \mathrm{E} / 13.67^{\circ} \mathrm{N}\right)$ with a time lead of $\sim 10 \mathrm{hrs}$ but other parameters remain more or less unchanged.
\end{abstract}

\section{Introduction}

In the last decade a total of 29 cyclones were formed in Bay of Bengal, 9 in premonsoon and 20 in postmonsoon, out of which 7 cyclones were very severe cyclonic storms (VSCS) and 6 cyclones were severe cyclonic storms (SCS). Most of these tropical cyclones formed over Bay of Bengal (BoB) region move generally in the north-west direction and cross the east coast of India. The east coast of India is known to be highly vulnerable to damage due to tropical cyclones because of the plain coastal terrain, developmental activity, and large population. Therefore it is desirable to have as much an accurate prediction as possible of the track and landfall of cyclones for effective implementation of the disaster management. Mesoscale numerical models based on well defined dynamical and physical processes have been increasingly used for the forecasting the movement and intensity of the storms.
The forecast performance of the mesoscale models critically depends on the quality of initial conditions. Typically, large scale global analyses provide the initial condition to the mesoscale models. These initial conditions have limitations, such as coarse resolution and inadequate representation of localized mesoscale features. Therefore, data assimilation techniques facilitate to combine all available past as well as current observations of the atmosphere to best define the initial state and thus to develop improved analyses (Kalnay [1]). Navon [2] has given a brief review of different data assimilation methods such as successive correction, optimum interpolation, and variational methods (3-DVAR, 4-DVAR) by highlighting their application in Numerical Weather Prediction (NWP) models. VinodKumar et al. [3] adopted four dimensional data assimilation (FDDA) and surface data assimilation to study tropical depressions over Bay of Bengal. The results suggested that improvement of monsoon 
depression simulations over $\mathrm{BoB}$ was equivalent, or better than that of increasing the model resolution from $30 \mathrm{~km}$ to $10 \mathrm{~km}$ grid spacing. Xavier et al. [4] studied the effect of assimilated satellite and conventional data on the prediction of three monsoon depressions over India using analysis nudging with MM5 (5th generation NCAR/Penn State Mesoscale Model) and found a positive overall impact on the model performance. An analysis of the status and developments of the four-dimensional variational data assimilation for mesoscale/storm-scale applications has been provided by Park and Zupanski [5]. They presented the theoretical background and the practical issues of 4-DVAR in terms of high-resolution observations, nonlinearity and discontinuity problem, model error, errors from lateral boundary conditions, and so forth, with applications to both hydrostatic and nonhydrostatic models. One of the problems in numerical modeling of tropical cyclones is the lack of conventional observations over the oceanic regions where cyclones form and develop. Satellite observations provide a very useful data for understanding and simulation of tropical cyclones because of their high spatial coverage, repetition, and resolution. Leslie et al. [6] have shown that the track of a hurricane could be better simulated with assimilation of high temporal and spatial resolution GOES-satellite-derived wind vectors using FDDA nudging. Marshall et al. [7] using continuous assimilation procedures like nudging reported that the Scatterometer winds were able to reduce the initial position error of cyclone. Zhang et al. [8] have studied the individual impacts of a number of satellite data on winds, temperature profiles on the initialization and forecasting of the rapid weakening of Hurricane Lili 2002, using MM5. In addition to the large amount of satellite information, assimilation of dropwindsonde data deployed from surveillance aircrafts is of utmost importance in numerical forecast of tropical cyclones. A number of recent studies have reported positive impact of dropwindsonde observations on hurricane track and intensity forecasts using various models (Kim et al. [9]). Several studies on simulation of tropical cyclones with different data sources and different assimilation techniques are reported over North Indian Ocean region (e.g., Mukhopadhyay et al. [10], Sandeep et al. [11], Vinodkumar et al. [3]), andd Srinivas et al. [12] did the simulation of BoB cyclone with FDDA technique using Weather Research \& Forecasting (WRF) model and reported that the combination of land-based surface, upper-air observations with the satellite winds for assimilation produced better prediction than the assimilation with individual data sets). Similar studies are carried out by Srinivas et al. [13] for Jal cyclone over Bay of Bengal.

The objective of the present study is to investigate the role of FDDA analysis nudging on the track and intensity of two severe cyclonic storms Aila (May 23-26, 2009) and Jal (Nov $4-8,2010)$ formed over the Bay of Bengal.

\section{Brief Description of Severe Cyclonic Storms}

2.1. Aila (May 23-26, 2009). According to RSMC [14], under the influence of increased low level convergence due to the onset of SW monsoon over Andaman Sea and adjoining south BoB on May 20, a low pressure area developed over the southeast $\mathrm{BoB}$ on May 22 morning. Under favorable conditions, like warmer sea surface temperature (SST) and low vertical wind shear, it concentrated into depression and further into deep depression at 03 UTC of May 24 near $18^{\circ} \mathrm{N} / 88.5^{\circ} \mathrm{E}$. Continuing its northerly movement, on $12 \mathrm{UTC}$ of May 24, it reached the cyclonic storm stage. With Central Sea Level Pressure (CSLP) of $974 \mathrm{hPa}$ and Maximum Surface Winds (MWS) $29 \mathrm{~m} \mathrm{~s}^{-1}$, it attained its severe cyclonic storm stage at 0600 UTC of May 25 over northwest BoB near $21.5^{\circ} \mathrm{N} / 88.0^{\circ} \mathrm{E}$ close to Sagar Island. The system crossed West Bengal coast close to the east of Sagar Island between 0800 and 0900 UTC and immediately after landfall it had its maximum intensity with CSLP of $967 \mathrm{hPa}$ and MSW as $31 \mathrm{~ms}^{-1}$ (Figure 2(a)). Under the influence of cyclone Aila, widespread rain/thundershowers with scattered heavy to very heavy rainfall and isolated extremely heavy rainfall $(\geq 25 \mathrm{~cm})$ occurred over Orissa on May 25 and over West Bengal and Sikkim on May 25 and 26. The special features of the cyclone Aila are its northerly movement throughout its life period, and its rapid intensification just before the landfall. It maintained its cyclone intensity upto 15 hours after landfall.

2.2. Jal (Nov 4-8, 2010). A severe cyclone "Jal" over the $\mathrm{BoB}$ is the remnant of a depression which moved from the northwest Pacific Ocean to the BoB across Thailand. It concentrated into deep depression at 00 UTC of Nov 5 near $9.0^{\circ} \mathrm{N} / 88.5^{\circ} \mathrm{E}$ and further intensified into severe cyclone at 2100 UTC of Nov 5, and lay centered around 10.0N/86E, with maximum intensity of CSLP $988 \mathrm{hPa}$ and MSW $31 \mathrm{~ms}^{-1}$ for $12 \mathrm{hrs}$ from 12 UTC Nov 6. It weakened into a cyclonic storm at 0600 UTC of Nov 7 over southwest BoB about $250 \mathrm{~km}$ east-southeast of Chennai and further into a deep depression on $12 \mathrm{UTC}$ of Nov 7 near $13.0^{\circ} \mathrm{N} / 81^{\circ} \mathrm{E}$. It crossed north Tamilnadu-south Andhra Pradesh coast, close to the north of Chennai near $13.3^{\circ} \mathrm{N} / 80.3^{\circ} \mathrm{E}$ around 1600 UTC of Nov 7 (Figure 4(a)). It continued to move west-northwestwards, and further weakened into a depression at 0300 UTC and into a well marked low pressure area over Rayalseema and adjoining south interior Karnataka at 0600 UTC of Nov 8. Rainfall occurred at most places with heavy to very heavy fall at a few places over north Tamil Nadu, Puducherry, coastal Andhra Pradesh, Rayalseema, south Interior Karnataka, and coastal Karnataka. The salient feature of the cyclone Jal is that it weakened into deep depression over the sea before the landfall (RSMC [15]).

\section{Model Description and Experimental Design}

3.1. WRF Model. The non-hydrostatic fully compressible Advanced Research Weather Research and Forecasting (WRF-ARW) model developed by National Center for Atmospheric Research (NCAR) is suitable for a broad range of applications, such as idealized simulations, parameterization research, data-assimilation research, and real-time numerical weather prediction (NWP). In the present study, cumulus parameterization scheme (CPS) such as Betts-Miller-Janjic (BMJ), Microphysics Parameterization Scheme (MPS-WRF Single Moment (WSM) 6-class, and Planetary Boundary 


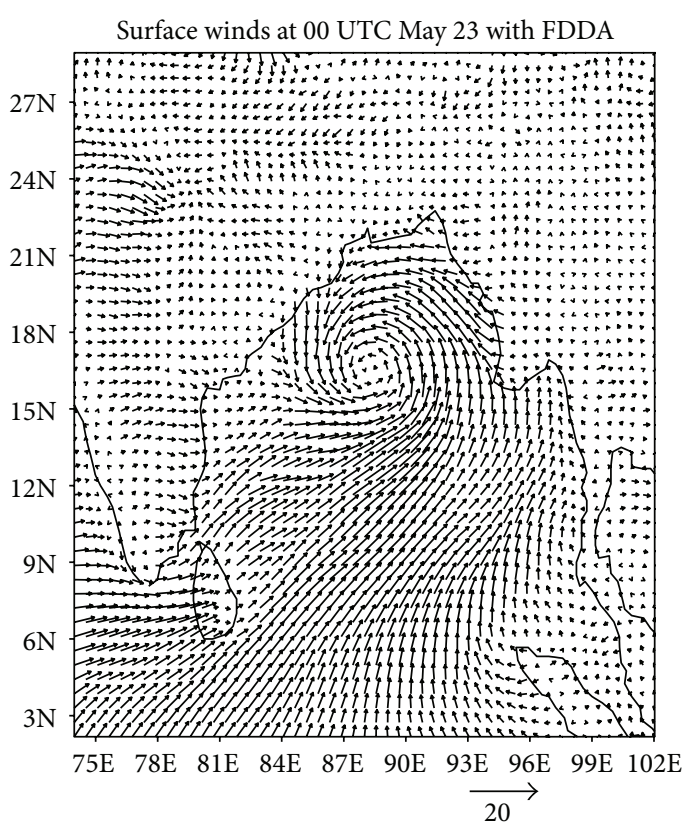

(a)

Relative vorticity (surface) at 00 UTC May 23 with FDDA

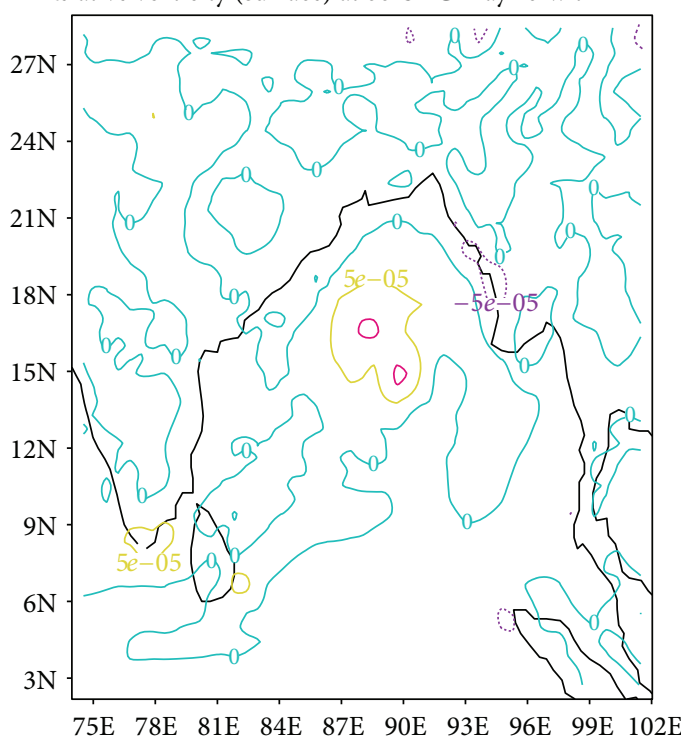

(c)

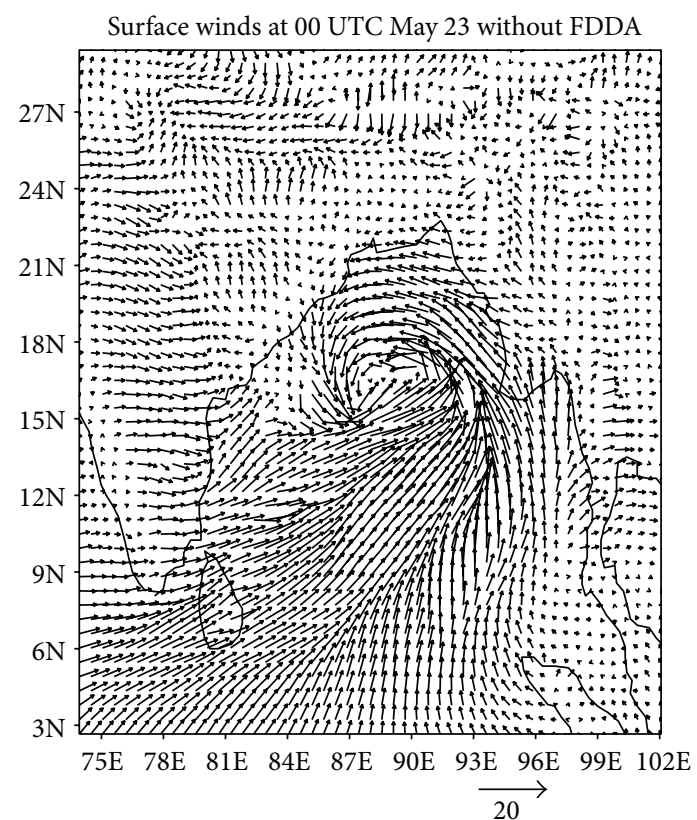

(b)

Relative vorticity (surface) at 00 UTC May 23 without FDDA

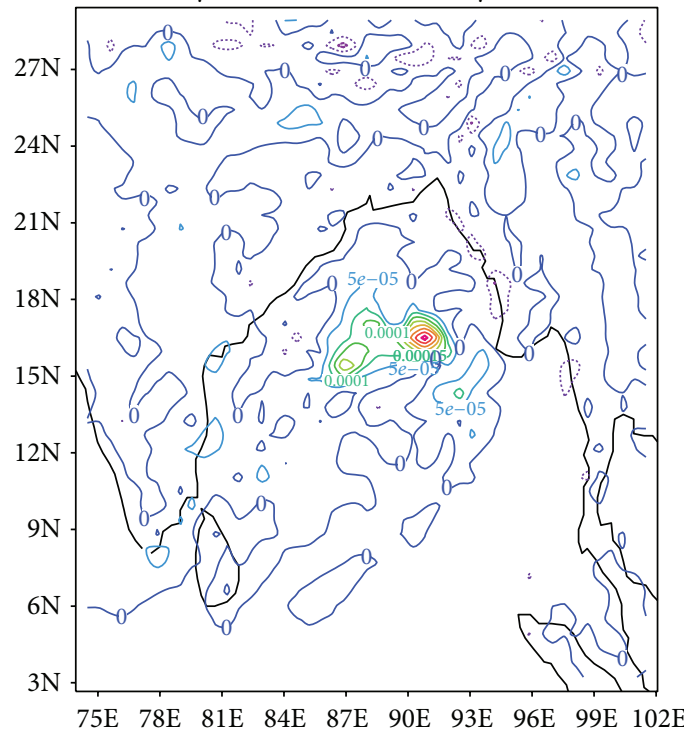

(d)

FIgURE 1: Upper panel: Surface winds at 00 UTC of May 23, 2009 (a) with FDDA and (b) without FDDA for Aila cyclone. Lower panel: surface relative vorticity at $00 \mathrm{UTC}$ of May 23, 2009 (c) with FDDA (d) without FDDA for Aila cyclone.

Layer (PBL) scheme-Yonsei University (YSU) are considered and kept same for all the model runs.

The detailed descriptions of model formulation, horizontal and vertical discretization, and time integration schemes used are given in Skamarock et al. [16].

3.2. Experimental Design. WRF model version 3.2.1 with three nested domains $(60,20$, and $6.6 \mathrm{~km})$ having two-way interaction is used in the present study. The model topography for the 60,20,d and $6.6 \mathrm{~km}$ domain regions are obtained from the USGS topography data at $10^{\prime}, 5^{\prime}$, and $2^{\prime}$ resolutions. Initial and boundary conditions are used from FNL (Final reanalysis) data of $1^{\circ} \times 1^{\circ}$ resolutions and Real Time Global (RTG) SST. For the experiments without FDDA, NCEPFNL data alone is used as initial and boundary conditions and for the experiments with FDDA, additional observations (from NCEP ADP Global Upper Air and Surface data which include radiosondes, pilot balloons, aircraft, and satellite data) are used. In all the experiments, FDDA is considered only in the outer domain for a $24 \mathrm{~h}$ preforecast period and 


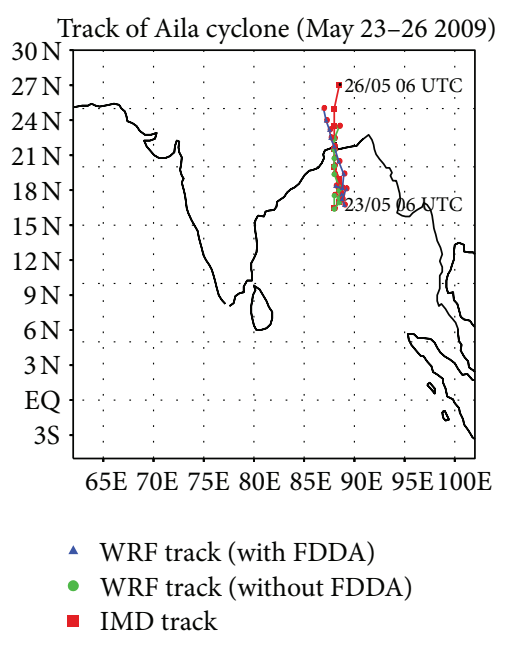

(a)

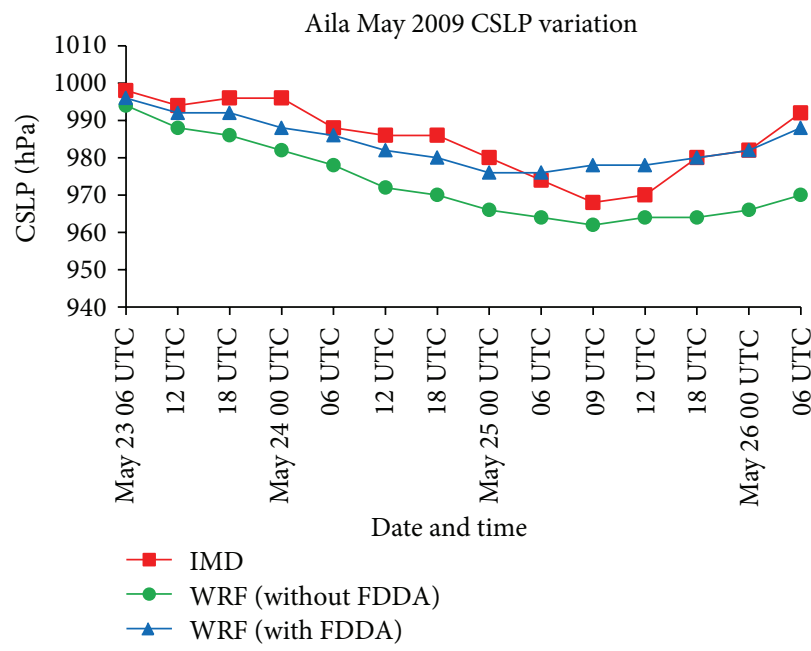

(c)

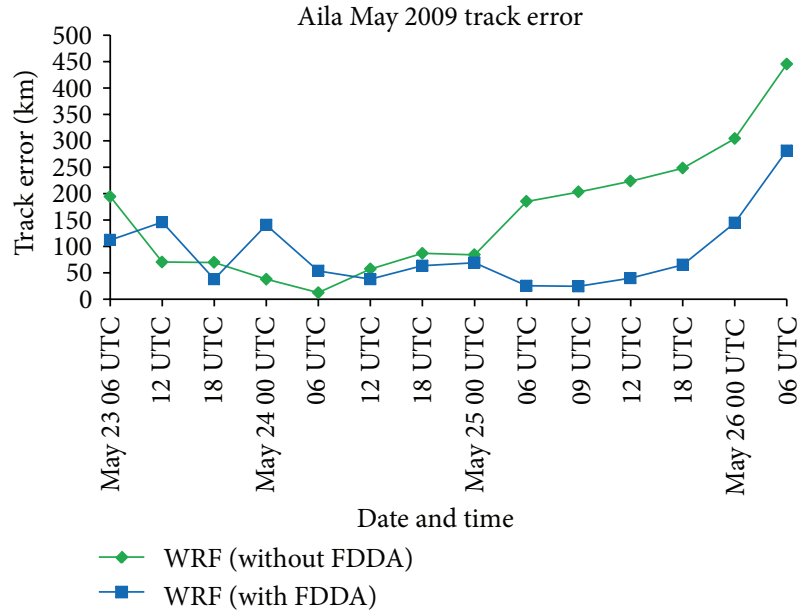

(b)

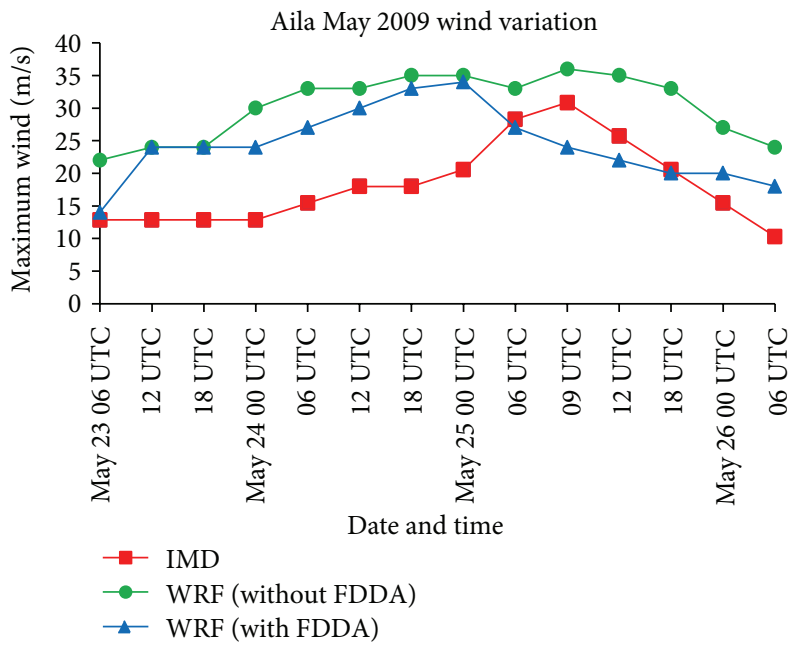

(d)

FIGURE 2: (a) Track of Aila cyclone, (b) variation of track error, (c) variation of CSLP, and (d) variation of maximum surface wind for Aila cyclone.

then the inner domain of $20 \mathrm{~km}$ is introduced. FDDA is a continuous data assimilation technique in which the model state is relaxed toward the observed state by augmenting some of the prognostic equations with forcing terms based on the difference between the observed state and the model state. Analysis nudging method is used in this work, in which the model solution is nudged toward time- and spaceinterpolated analyses using a point-by-point relaxation term (Stauffer and Seaman [17, 18], Stauffer et al. [19]).

\section{Results and Discussion}

The case of Aila (May 23-26, 2009) cyclone, during premonsoon period, is considered. The model integration is started from 00 UTC of May 22, 2009 which corresponds to the low pressure area state in the observation. In FDDA experiment, nudging technique is applied for a pre-forecast period of $24 \mathrm{hrs}$ and then the free forecast is observed. For other experiment, it is a control run without FDDA. After $24 \mathrm{hrs}$ of model integration (at 00U TC of May 23, 2009), surface winds are observed for with and without FDDA experiments as shown in Figures 1(a) and 1(b). The surface winds are seen to be well organized for FDDA experiment whereas the circulation fields with wide area and with disturbed vortex are clearly seen in other experiment. The magnitude of winds is found to be larger for other experiment but it is reduced in FDDA experiment (Figures 1(a) and 1(b)). To see the wind fields in more detail, the surface relative vorticity fields are plotted at the same time in Figures 1(c) and 1(d). The decrease in the cyclonic vorticity values (10e-5) is clearly seen when compared with the vorticity values $(35 \mathrm{e}-5)$ in other experiment. Also the maximum cyclonic vorticity center seems to be wider in other experiment. In short, the strength of relative vorticity is found 


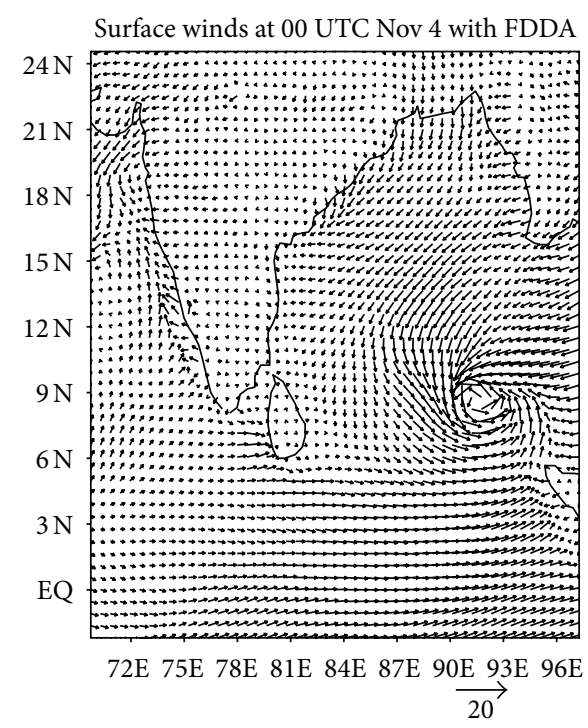

(a)

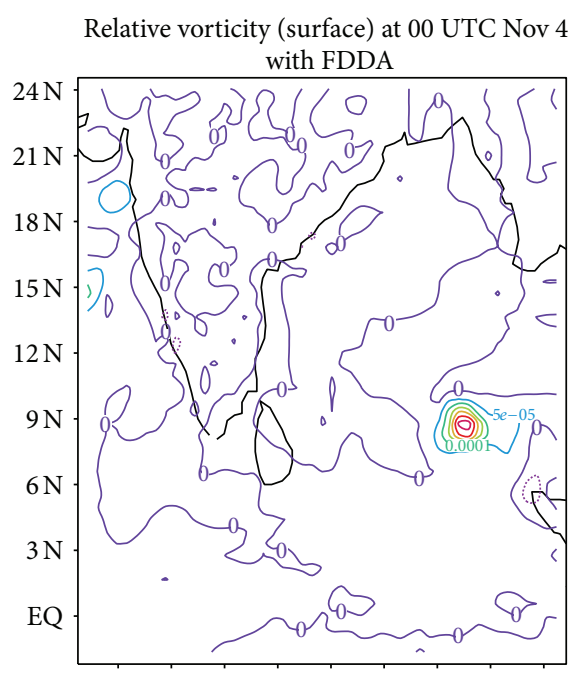

72E $75 \mathrm{E} 78 \mathrm{E} 81 \mathrm{E} 84 \mathrm{E} 87 \mathrm{E} 90 \mathrm{E} 93 \mathrm{E} 96 \mathrm{E}$

(c)
Surface winds at 00 UTC Nov 4 without FDDA

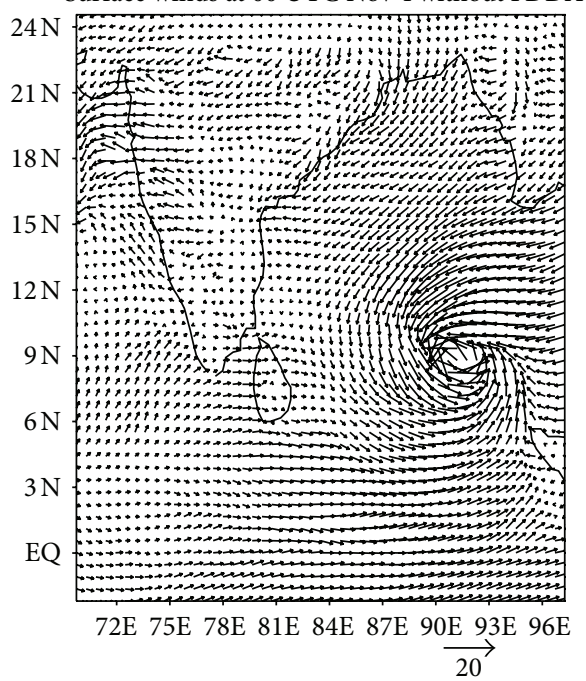

(b)

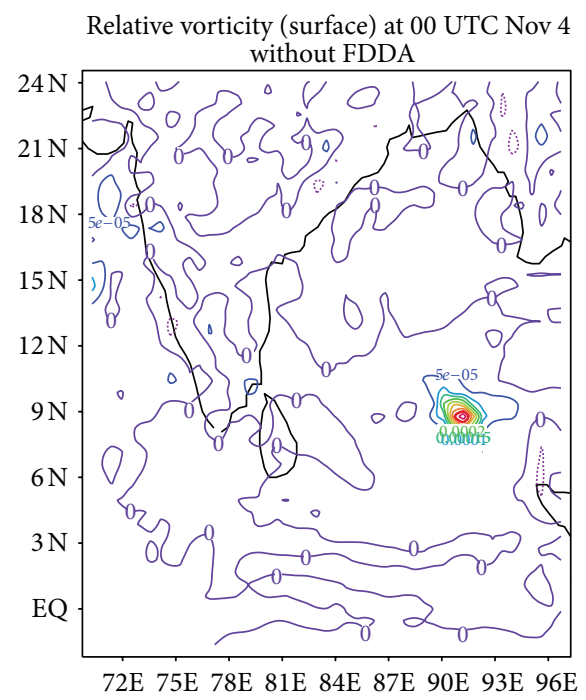

(d)

FIGURE 3: Upper panel: surface winds at 00 UTC of Nov 42010 (a) with FDDA and (b) without FDDA for Jal cyclone. Lower panel: surface relative vorticity at 00 UTC of Nov 42010 (c) with FDDA and (d) without FDDA for Jal cyclone.

to be weakened (Figures $1(\mathrm{c})$ and $1(\mathrm{~d})$ ). The observed and model simulated surface tracks are shown in Figure 2(a). Both the experiments show the overlapped track on the India Meteorological Department (IMD) observed track. In order to understand it quantitatively, the time evolution of track error for every $6 \mathrm{hrs}$ is plotted in Figure 2(b). For without FDDA experiment, initially track error is found to be decreased with $12 \mathrm{~km}$ as its minimum value upto 06 UTC May 24 and thereafter it continuously increases and reaches $\sim 450 \mathrm{~km}$. In case of FDDA experiment, initially it appears that the track error is increasing upto 06 UTC May 24, but thereafter it is lower than $50 \mathrm{~km}$. This indicates that the error in the landfall is low when FDDA technique is applied. The intercomparison between the different parameters for both cyclones is summarized in Table 1. As landfall position and landfall time are very important for the mitigation purpose, for FDDA experiment landfall time is $2-3 \mathrm{hrs}$ prior to the observed landfall and landfall position is found to be $25 \mathrm{~km}$ away from the observed position. This error in landfall time and position is more in other experiments. Similarly the intensity of Aila is represented by Central Sea Level Pressure (CSLP) and Maximum Surface Wind (MSW) and is shown in Figures 2(c) and 2(d). Simulated intensity (CSLP) is underestimated for FDDA experiment while it is overestimated for other experiments. Careful observation indicates that simulated intensity with FDDA experiment is very close to the observations over the oceanic region and it is underestimated thereafter. But MSW values are relatively closer to the observations for FDDA experiment. This change in the intensity values is maybe due to the modification 


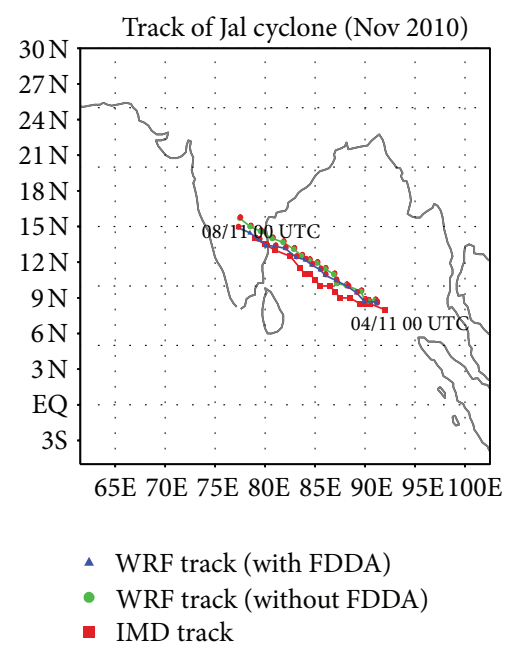

(a)

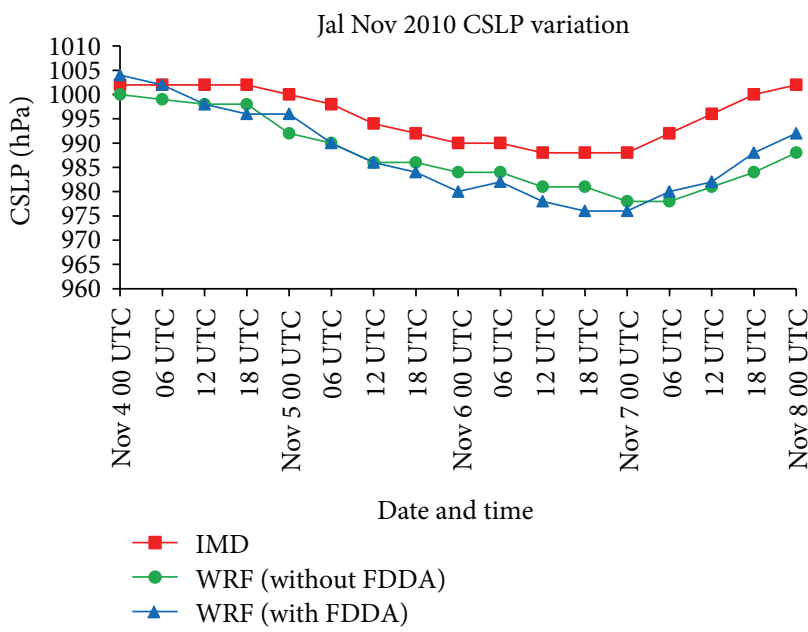

(c)

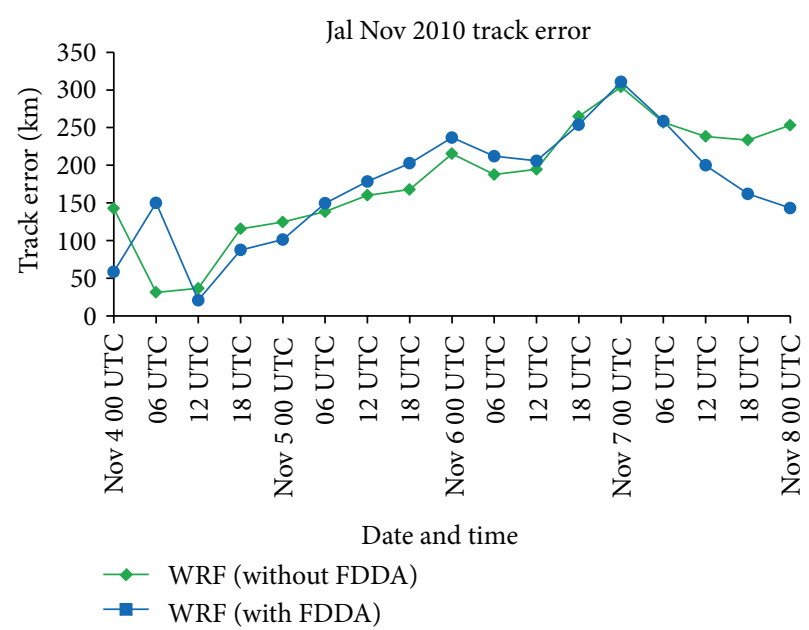

(b)

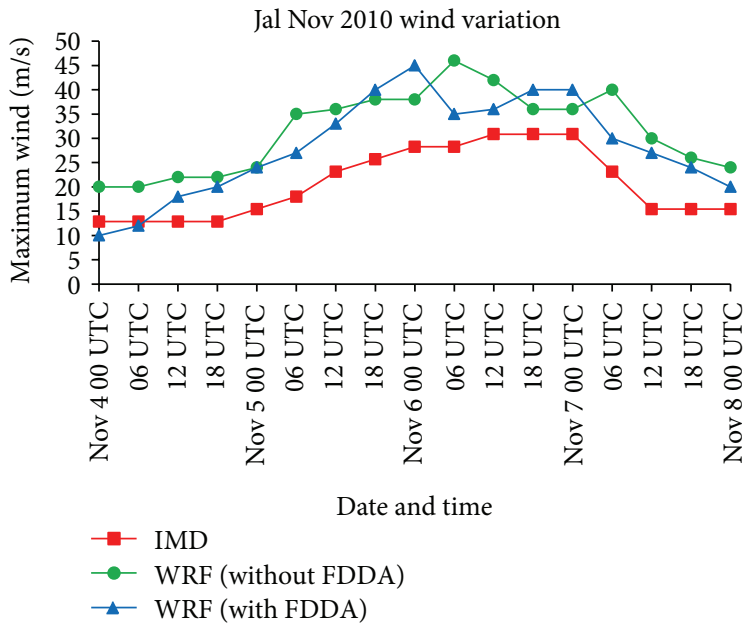

(d)

FIGURE 4: (a) Track of Jal cyclone, (b) variation of track error, (c) variation of CSLP, (d) variation of maximum surface wind for Jal cyclone.

TABLE 1: Comparison of observed parameters with simulated parameters for cyclone Aila and Jal.

\begin{tabular}{lccccc}
\hline Cyclone & Experiment & Landfall time & Landfall Position & CSLP (hPa) & MSW (m/s) \\
\hline \multirow{3}{*}{ Aila } & Observed (IMD) & 08 and 09 UTC of May 25 & $88 \mathrm{E} / 21.8 \mathrm{~N}$ & 968 & 30.84 \\
& WRF with FDDA & 06 UTC of May 25 2009 & $88 \mathrm{E} / 21.73 \mathrm{~N}$ & 976 & 34 \\
& Without FDDA & Bet. 9-12 UTC of May 25 & $87.13 \mathrm{E} / 20.37 \mathrm{~N}$ & 962 & 36 \\
\hline \multirow{3}{*}{ Jal } & Observed (IMD) & Near 16 UTC of Nov. 7 & $80.2 \mathrm{E} / 13.3 \mathrm{~N}$ & 988 & 30.84 \\
& WRF with FDDA & Near 06 UTC of Nov. 7 & $80.16 \mathrm{E} / 13.67 \mathrm{~N}$ & 976 & 40 \\
& Without FDDA & Bet. 6-12 UTC of Nov. 7 & $79.54 \mathrm{E} / 14.6 \mathrm{~N}$ & 978 \\
\hline
\end{tabular}

or change in the initial wind fields caused by the FDDA technique (Figures 1(a) and 1(b)).

In order to verify the results, another case of Post monsoon severe cyclone Jal (Nov 4-8, 2010) is considered. For Jal cyclone also two experiments-one with FDDA technique and another without FDDA-are carried out. The FDDA nudging is applied for pre-forecast period of $24 \mathrm{hrs}$ (upto 00 UTC Nov 4) and then free forecast starts. The surface wind fields after 24 hrs of integration, that is, at 00 UTC of Nov 4 are shown in Figures 3(a) and 3(b). For FDDA experiment, surface circulation is found to be well organized whereas the vortex is found to be narrow in other experiments. The magnitude of surface wind fields does not show remarkable change in both the experiments. But the slight reduction in the magnitude of relative vorticity is clearly depicted from Figures 3(c) and 3(d). The IMD observed surface track and 
model simulated tracks are shown in Figure 4(a). Initially, tracks of both experiments are overlapped on each other and remain more or less at the same distance from the observed track. But when cyclone approaches towards the land, the track in FDDA experiment lies very close to the observed track. This can be clearly seen from the track error plot (Figure 4(b)). The track error is found to be reduced after simulated landfall for FDDA experiment. Landfall position is simulated accurately (track error $\sim 37 \mathrm{~km}$ at the landfall point) with FDDA experiment when compared with other experiment. Both experiments show early landfall but landfall in case of experiment without FDDA is close to the observed landfall. When the intensity (CSLP and MSW) is compared with the observed intensity, it is overestimated in both experiments and remains more or less unchanged (Figures $4(\mathrm{c})$ and $4(\mathrm{~d}))$. The very small change in the landfall position, landfall time, intensity, and the track error may be associated with the small changes in the initial fields especially in the wind fields.

\section{Conclusions}

The analysis nudging technique applied in the research work shows improvement in the wind fields and thus improved and well organized vortex for the pre-monsoon cyclone Aila and no remarkable improvement is noticed for the post monsoon cyclone Jal. The track, intensity, landfall position, and time for Aila are very close to the observations in the FDDA experiment. For Jal cyclone, FDDA played significant role to improve the landfall position $\left(80.16^{\circ} \mathrm{E} / 13.67^{\circ} \mathrm{N}\right)$ with a time lead of $\sim 10$ hrs but other parameters remain more or less unchanged. It needs to be verified with a greater number of pre- and post monsoon cyclone cases.

\section{Acknowledgments}

The authors wish to thank the Director, Indian Institute of Tropical Meteorology (IITM), Pune, for his encouragement and support. Authors acknowledge the use of WRF-ARW model, which is made available on the Internet by the Mesoscale and Microscale division of NCAR. The use of NCEPFNL data, RTG-SST data, IMD observations, and GrADS software is acknowledged with thanks.

\section{References}

[1] E. Kalnay, Atmospheric Modeling, Data Assimilation and Predictability, Cambridge University Press, London, UK, 2003.

[2] I. M. Navon, "Data assimilation for numerical weather prediction: a review," in Data Assimilation For Atmospheric, Oceanic And Hydrologic Applications, S. K. Park and L. Xu, Eds., pp. 2165, Springer, Berlin, Germany, 2009.

[3] Vinodkumar, A. Chandrasekar, K. Alapaty, and D. S. Niyogi, "The effect of a surface data assimilation technique and the traditional four-dimensional data assimilation on the simulation of a monsoon depression over India using a mesoscale model," Natural Hazards, vol. 42, no. 2, pp. 439-453, 2007.

[4] V. F. Xavier, A. Chandrasekar, H. Rahman, D. Niyogi, and K. Alapaty, "The effect of satellite and conventional meteorological data assimilation on the mesoscale modeling of monsoon depressions over India," Meteorology and Atmospheric Physics, vol. 101, no. 1-2, pp. 65-92, 2008.

[5] S. K. Park and D. Zupanski, "Four-dimensional variational data assimilation for mesoscale and storm-scale applications," Meteorology and Atmospheric Physics, vol. 82, no. 1-4, pp. 173208, 2003.

[6] L. M. Leslie, J. F. Lemarshall, R. P. Morison et al., "Improved hurricane track forecasting from the continuous assimilation of high quality satellite wind data," Monthly Weather Review, vol. 126, no. 5, pp. 1248-1257, 1998.

[7] J. Le Marshall, L. Leslie, R. Morison, N. Pescod, R. Seecamp, and C. Spinoso, "Recent developments in the continuous assimilation of satellite wind data for tropical cyclone track forecasting," Advances in Space Research, vol. 25, no. 5, pp. 10771080, 2000.

[8] X. Zhang, Q. Xiao, and P. J. Fitzpatrick, "The impact of multisatellite data on the initialization and simulation of Hurricane Lili's (2002) rapid weakening phase," Monthly Weather Review, vol. 135, no. 2, pp. 526-548, 2007.

[9] Y. H. Kim, E. H. Jeon, D. E. Chang, H. S. Lee, and J. I. Park, “The impact of T-PARC 2008 dropsonde observations on typhoon track forecasting," Asia-Pacific Journal of Atmospheric Sciences, vol. 46, no. 3, pp. 287-303, 2010.

[10] P. Mukhopadhyay, J. Sanjay, W. R. Cotton, and S. S. Singh, "Impact of surface meteorological observations on RAMS forecast of monsoon weather systems over the Indian region," Meteorology and Atmospheric Physics, vol. 90, no. 1-2, pp. 77108, 2005.

[11] S. Sandeep, A. Chandrasekar, and D. Singh, "The impact of assimilation of AMSU data for the prediction of a tropical cyclone over India using a mesoscale model," International Journal of Remote Sensing, vol. 27, no. 20, pp. 4621-4653, 2006.

[12] C. V. Srinivas, V. Yesubabu, R. Venkatesan, and S. S. V. S. Ramarkrishna, "Impact of assimilation of conventional and satellite meteorological observations on the numerical simulation of a Bay of Bengal Tropical Cyclone of November 2008 near Tamilnadu using WRF model," Meteorology and Atmospheric Physics, vol. 110, no. 1, pp. 19-44, 2010.

[13] C. V. Srinivas, V. Yesubabu, K. B. R. R. Hariprasad, S. S. V. Ramakrishna, and B. Venkatraman, "Real-time prediction of a severe cyclone 'Jal' over Bay of Bengal using a high-resolution mesoscale model WRF (ARW)," Natural Hazards, vol. 65, no. 1, pp. 331-357, 2013.

[14] "A report on cyclonic disturbances over North Indian Ocean during 2009," RSMC Report, India Meteorological Department, New Delhi, India, 2010.

[15] "A report on cyclonic disturbances over North Indian Ocean during 2010," RSMC Report, India Meteorological Department, New Delhi, India, 2011.

[16] W. C. Skamarock, J. B. Klemp, J. Dudhia et al., "A description of the Advanced Research WRF version 3," NCAR Technical Note 475, 2008, http://www.mmm.ucar.edu/wrf/users/ docs/arw_v3.pdf.

[17] D. R. Stauffer and N. L. Seaman, "Use of four-dimensional data assimilation in a limited-area mesoscale model. Part I: experiments with synoptic-scale data," Monthly Weather Review, vol. 118, no. 6, pp. 1250-1277, 1990.

[18] D. R. Stauffer and N. L. Seaman, "Multiscale four-dimensional data assimilation," Journal of Applied Meteorology, vol. 33, no. 3, pp. 416-434, 1994. 
[19] D. R. Stauffer, N. L. Seaman, and F. S. Binkowski, "Use of four-dimensional data assimilation in a limited-area mesoscale model Part II: effects of data assimilation within the planetary boundary layer," Monthly Weather Review, vol. 119, no. 3, pp. 734-754, 1991. 

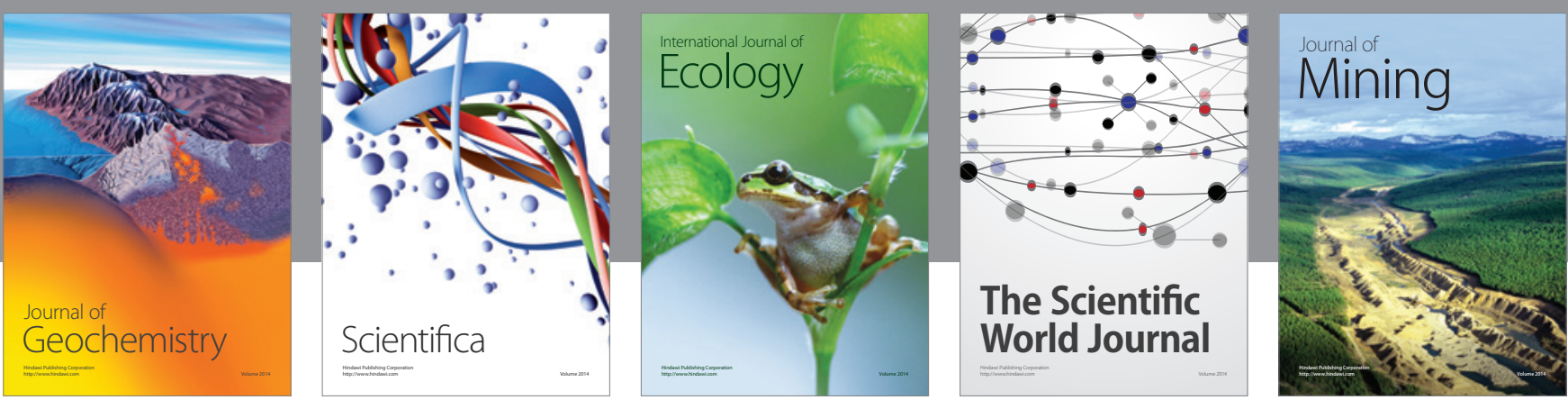

The Scientific World Journal
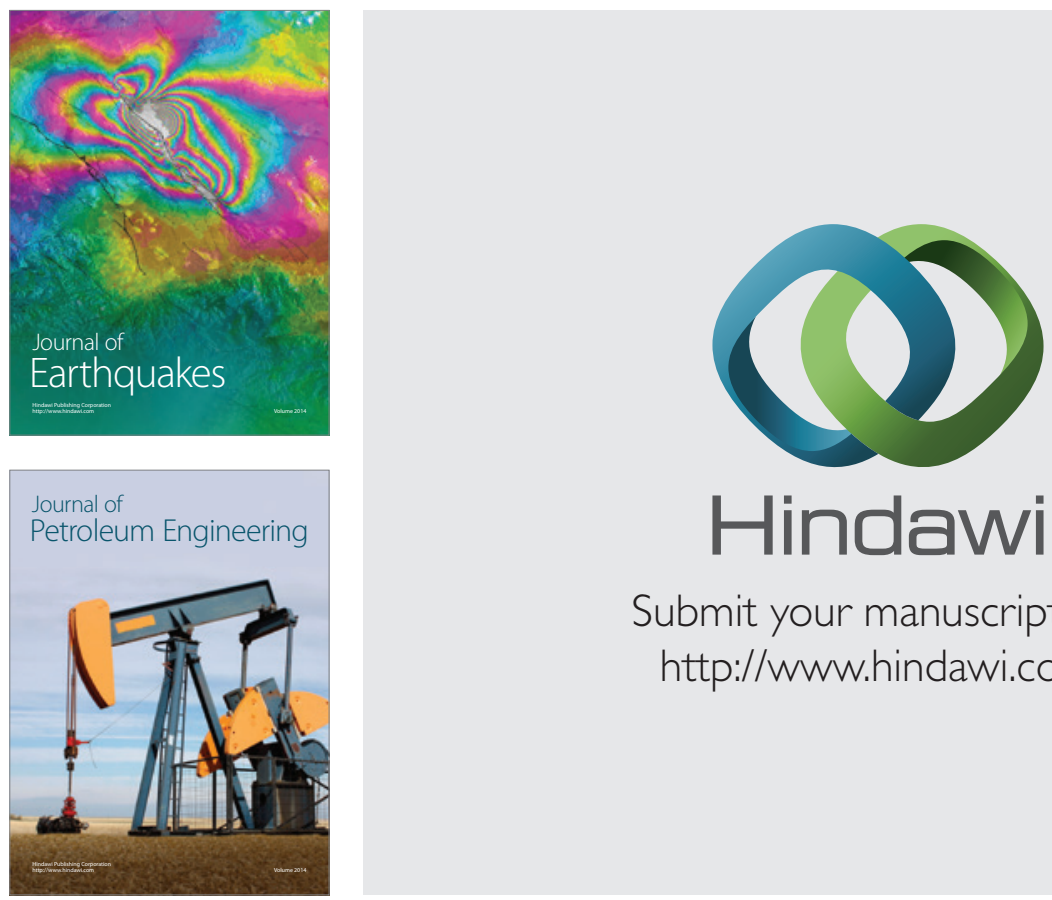

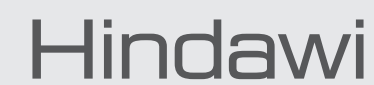

Submit your manuscripts at

http://www.hindawi.com
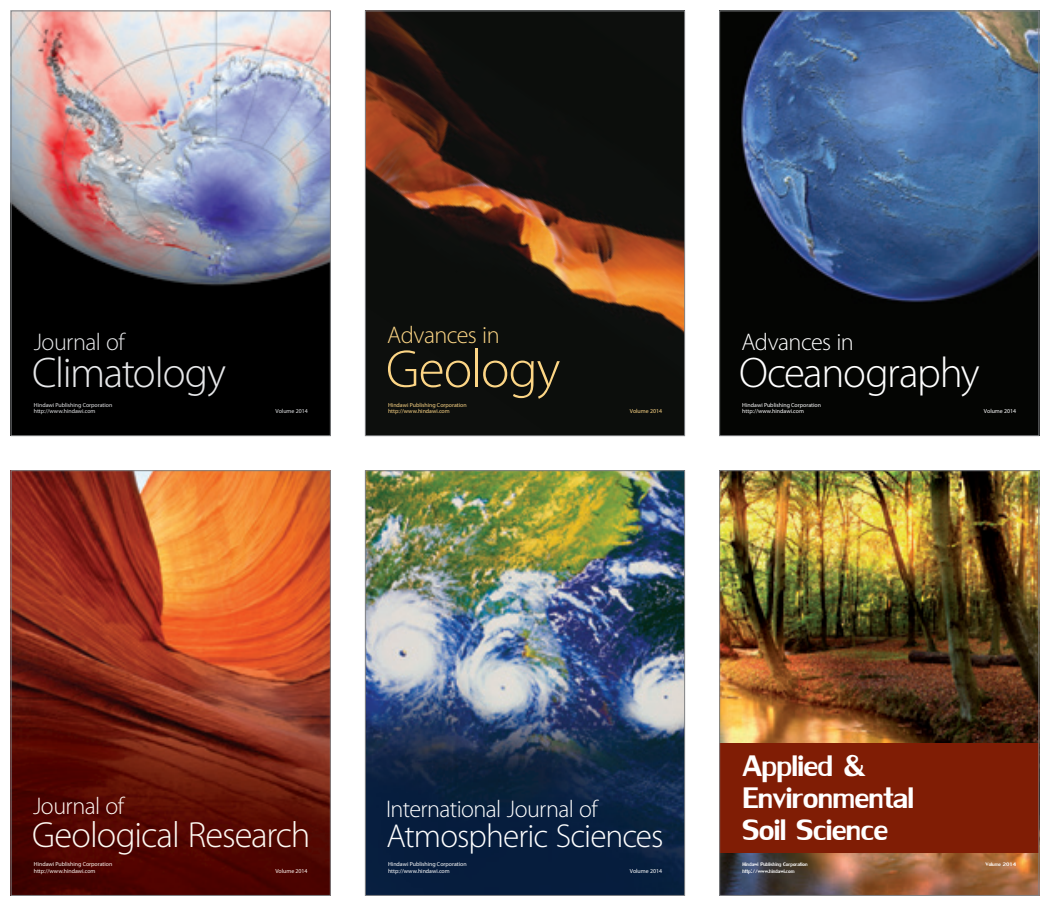
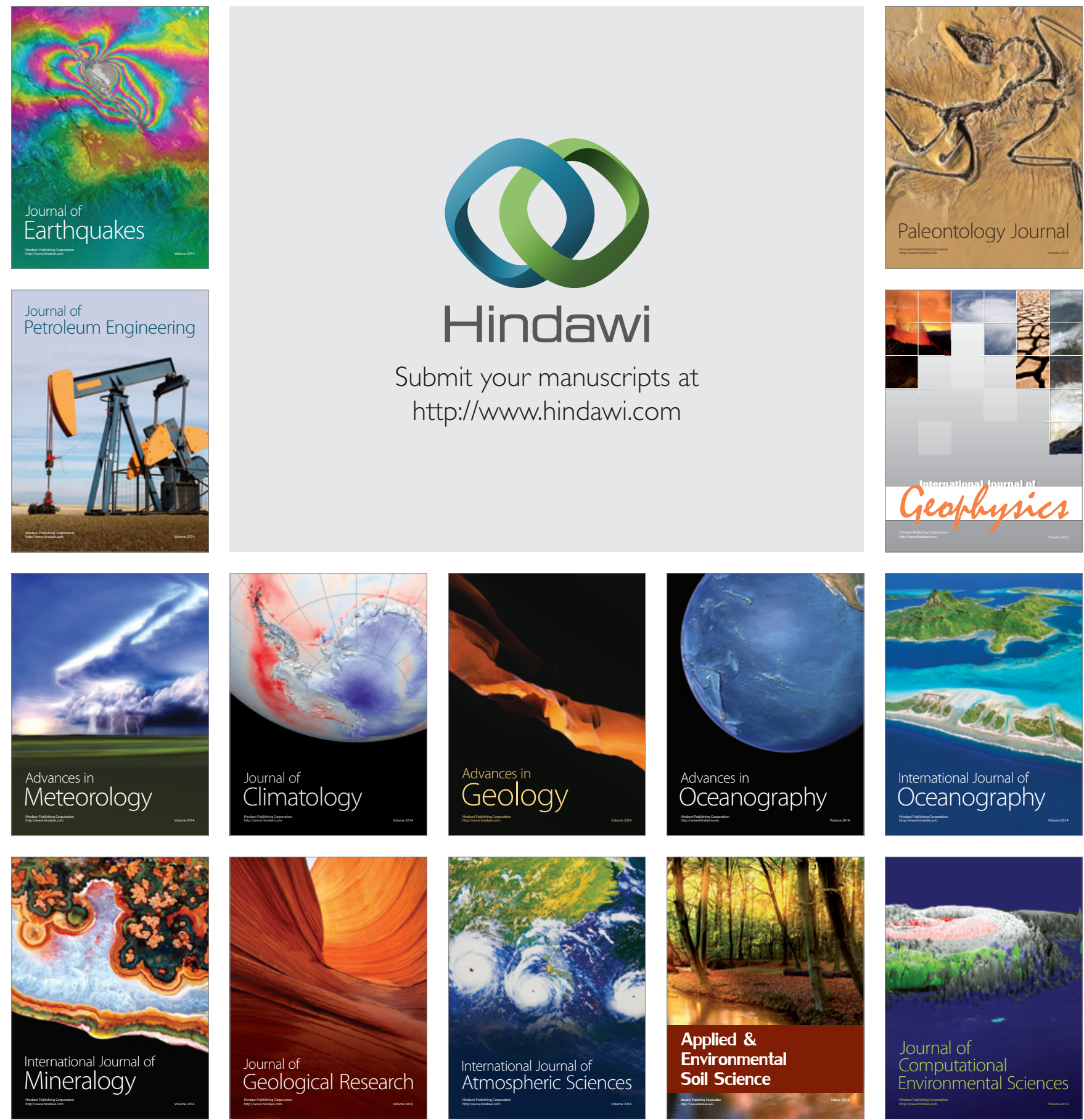